\title{
Anti-Inflammatory Drug Therapy Alters $\beta$-Amyloid Processing and Deposition in an Animal Model of Alzheimer's Disease
}

\author{
Qiao Yan, ${ }^{1}$ Jianhua Zhang, ${ }^{1}$ Hantao Liu, ${ }^{1}$ Safura Babu-Khan, ${ }^{1}$ Robert Vassar, ${ }^{1}$ Anja Leona Biere, ${ }^{1}$ Martin Citron, ${ }^{1}$ and \\ Gary Landreth ${ }^{2}$ \\ ${ }^{1}$ Department of Neuroscience, Amgen Inc., Thousand Oaks, California 91320, and ${ }^{2}$ Alzheimer Research Laboratory, Department of Neurosciences, Case \\ Western Reserve University, Cleveland, Ohio 44106
}

\begin{abstract}
Alzheimer's disease (AD) is characterized by a microglial-mediated inflammatory response elicited by extensive amyloid deposition in the brain. Nonsteroidal anti-inflammatory drug (NSAID) treatment reduces AD risk, slows disease progression, and reduces microglial activation; however, the basis of these effects is unknown. We report that treatment of 11-month-old Tg2576 mice overexpressing human amyloid precursor protein (APP) with the NSAID ibuprofen for 16 weeks resulted in the dramatic and selective reduction of SDS-soluble $\beta$-amyloid $(\mathrm{A} \beta)_{42}$, whereas it had smaller effects on SDS-soluble $\mathrm{A} \beta_{40}$ levels. Ibuprofen treatment resulted in $60 \%$ reduction of amyloid plaque load in the cortex of these animals. In vitro studies using APP-expressing 293 cells showed that ibuprofen directly affected APP processing, specifically reducing the production of $\mathrm{A} \beta_{42}$. Ibuprofen treatment resulted in a significant reduction in microglial activation in the Tg2576 mice, as measured by CD45 and CD11b expression. NSAIDs activate the nuclear hormone receptor peroxisome proliferatoractivated receptor $\gamma(\operatorname{PPAR} \gamma)$; however, a potent agonist of this receptor, pioglitazone, only modestly reduced SDS-soluble A $\beta$ levels and did not affect amyloid plaque burden or microglia activation, indicating that PPAR $\gamma$ activation is not involved in the A $\beta$ lowering effect of NSAIDs. These data show that chronic NSAID treatment can reduce brain A $\beta$ levels, amyloid plaque burden, and microglial activation in an animal model of Alzheimer's disease.
\end{abstract}

Key words: Alzheimer's disease; NSAIDs; $\beta$-amyloid; PPAR $\gamma$; inflammation; microglia

\section{Introduction}

Alzheimer's disease (AD) is characterized by the deposition of fibrillar forms of $\beta$-amyloid (A $\beta$ ) in the brain and the compaction of the $\mathrm{A} \beta$ fibrils into senile plaques (Akiyama et al., 2000). Several isoforms of $\mathrm{A} \beta$ are proteolytically generated when $\beta$-secretases and $\gamma$-secretases cleave the large amyloid precursor protein (APP). Although $\mathrm{A} \beta_{40}$ is the predominant cleavage product in vitro and in vivo, the less abundant and less soluble $\mathrm{A} \beta_{42}$, which contains two additional C-terminal hydrophobic amino acids, is generally considered the key pathogenic $\mathrm{A} \beta$ species, and modulation of its production may have therapeutic value (for review, see Citron, 2002). The focal deposits of $A \beta$ elicit a significant microglial-mediated inflammatory response. Microglia associate with the fibrillar $A \beta$, invest the plaque with their processes (Stalder et al., 2001), and undergo a phenotypic activation. Microglial activation is accompanied by the elaboration of a wide range of proinflammatory molecules that mediate the fulminating autoactivation of these cells and a concomitant astrocytosis. The inflammatory response is associated with the demise of neu-

Received Jan. 21, 2003; revised May 29, 2003; accepted June 3, 2003.

We thank the members of the Amgen animal facility for invaluable assistance with this study.

Correspondence should be addressed to Dr. Martin Citron, Amgen, M/S 29-2-B, One Amgen Center Drive, Thousand 0aks, CA 91320-1799. E-mail: mcitron@amgen.com.

R. Vassar's present address: Feinberg School of Medicine, Northwestern University, Chicago, IL 60611.

Copyright $\odot 2003$ Society for Neuroscience $\quad$ 0270-6474/03/237504-06\$15.00/0 rons adjacent to the plaques (Kalaria, 1999). Murine models of $\mathrm{AD}$ that overexpress APP and develop $\mathrm{A} \beta$ plaques also exhibit proinflammatory activation of microglial cells (Frautschy et al., 1998; Benzing et al., 1999; Stalder et al., 1999; Mehlhorn et al., 2000; Bornemann et al., 2001).

There is compelling epidemiological evidence that long-term nonsteroidal anti-inflammatory drug (NSAID) therapy has a dramatic effect on the incidence of AD (McGeer et al., 1996), resulting in a reduction of risk by as much as $60-80 \%$ (Stewart et al., 1997; in t' Veld et al., 2001). Moreover, NSAID treatment delays disease onset, acts to ameliorate symptomatic severity, and slows disease progression (Rich et al., 1995; Stewart et al., 1997). In humans, NSAID therapy results in a substantial reduction in the number of microglia associated with senile plaques, supporting the view that these cells are the targets of drug action (Mackenzie and Munoz, 1998). These findings have stimulated substantial interest in the biological basis of the effect of this class of drugs, especially in view of evidence that the accepted targets of the action of NSAIDs, the cyclooxygenases (COXs), are unlikely to mediate these effects (Sainati et al., 2000; Landreth and Heneka, 2001; Tegeder et al., 2001; Weggen et al., 2001).

Lim and colleagues (2000) reported the provocative finding that 6 months of treatment of a transgenic animal model of AD with the NSAID ibuprofen resulted in a significant reduction of amyloid plaque burden and in total $\mathrm{A} \beta$ peptide levels. These 
studies also demonstrated that ibuprofen treatment led to a reduction of plaque-associated microglia and a corresponding reduction in proinflammatory cytokine levels in the brain. Other NSAIDs have recently been reported to exhibit similar effects on amyloid pathology (Jantzen et al., 2002).

The mechanisms through which NSAIDs act to achieve these effects are presently unclear. In a compelling recent study, Weggen et al. (2001) reported that a subset of NSAIDs, including ibuprofen, acted to selectively suppress the production of the highly amyloidogenic $A \beta_{42}$ species both in vitro and in an acute treatment paradigm in vivo. NSAIDs also have poorly defined effects on intracellular signaling pathways (Tegeder et al., 2001), including those used by cytokines (Baek et al., 2002). A newly recognized target of NSAID action is the nuclear receptor and transcription factor peroxisome proliferator-activated receptor $\gamma$ (PPAR $\gamma$ ) (Lehmann et al., 1997; Berger and Moller, 2002). The binding of NSAIDs to PPAR $\gamma$ results in the inhibition of proinflammatory gene expression (Delerive et al., 2001). We suggested previously that NSAIDs may act to elicit the anti-inflammatory effects in the AD brain through an ability to bind to and activate $\operatorname{PPAR} \gamma$. PPAR $\gamma$ activation leads to inhibition of microglialmediated neurotoxicity and cytokine expression elicited by $\mathrm{A} \beta$ fibrils both in vitro (Combs et al., 2000) and in vivo (Heneka et al., 2000).

The aim of this study was to test whether the NSAID ibuprofen and the PPAR $\gamma$ agonist pioglitazone acted to suppress the development of amyloid pathology and inflammatory responses in the brains of APP-expressing Tg2576 transgenic mice. We report that 4 months of ibuprofen treatment resulted in a reduction in the plaque burden in these mice and a reduction in microglial activation. Significantly, ibuprofen treatment selectively reduced the levels of SDS-soluble $\mathrm{A} \beta_{42}$ in the brains of the APPoverexpressing mice. Pioglitazone had only modest effects on total $\mathrm{A} \beta$ levels, and it did not alter microglial activation, nor did it significantly affect amyloid plaque burden.

\section{Materials and Methods}

Materials. Ibuprofen was purchased from Sigma (St. Louis, MO). Pioglitazone $\mathrm{HCl}$ (ACTOS; Takeda Pharmaceuticals, Osaka, Japan) was obtained from a local pharmacy. These compounds were formulated into standard, color-coded, AIN-76A rodent diet by Research Diets (New Brunswick, NJ) at a final drug concentration of $120 \mathrm{ppm}$ pioglitazone and $375 \mathrm{ppm}$ ibuprofen. The dose of pioglitazone was selected on the basis of its ability to stimulate the transcriptional activation of PPAR $\gamma$-responsive genes in rodents. The dose of ibuprofen was the same as that used by Lim et al. (2000).

Drug treatment of Tg2576 mice. APP transgenic Tg2576 mice at 11 months old were fed the drug-supplemented chow ad libitum for 16 weeks. There were five animals in each treatment group. Animals were housed singly in individual cages, and their body weight and food consumption were monitored weekly. There were no significant differences in the amount of chow consumed or in weight of the mice during the experimental period, either within or between treatment groups. The food consumption of animals in this experiment was $\sim 5$ gm of rodent chow per day per animal, resulting in a final dose of pioglitazone of 20 $\mathrm{mg} \cdot \mathrm{kg}^{-1} \cdot \mathrm{d}^{-1}$ and ibuprofen of $62.5 \mathrm{mg} \cdot \mathrm{kg}^{-1} \cdot \mathrm{d}^{-1}$. At the end of the experimental period, animals were killed by inhalation of $\mathrm{CO}_{2}$. The brain was dissected and the hemispheres separated along the midline. Half of the brain was frozen on dry ice for A $\beta$ ELISA analysis. The other hemisphere was frozen in OCT medium for histological study.

Immunohistochemistry. Coronal sections $(14 \mu \mathrm{M})$ were cut on a cryostat microtome. Sections were thaw mounted onto Fisher "plus" microscope slides, air-dried, and then stored at $-20^{\circ} \mathrm{C}$ until use. Sections were warmed to room temperature and fixed in $4 \%$ paraformaldehyde $/ 0.1 \mathrm{M}$ phosphate buffer, $\mathrm{pH}$ 7.2, for $1 \mathrm{hr}$. The endogenous tissue peroxidase activity was quenched by incubation with $3 \% \mathrm{H}_{2} \mathrm{O}_{2}$ in PBS for 20 min. For $\mathrm{A} \beta$ immunohistochemistry, sections were subsequently incubated with $88 \%$ formic acid for 20 min to expose the A $\beta$ epitope. Sections were then incubated with blocking solution ( $3 \%$ normal goat serum, $5 \%$ normal horse serum, $0.25 \%$ carrageenan lambda, $0.1 \%$ Triton X-100 in PBS) for $1 \mathrm{hr}$. The primary antibodies used were biotinylated mouse antihuman A $\beta$ monoclonal antibody 4G8 (Signet Pathology System, Dedham, MA) at $0.5 \mu \mathrm{g} / \mathrm{ml}$, rat anti-CD45 monoclonal antibody (MCA 1388; Serotec, Raleigh, NC) at $0.2 \mu \mathrm{g} / \mathrm{ml}$, rat anti-CD11b monoclonal antibody (MAB 1387Z; Chemicon, Temecula, CA) at $5 \mu \mathrm{g} / \mathrm{ml}$, biotinylated mouse anti-phosphotyrosine monoclonal antibody (B-1531; Sigma) at $1 \mu \mathrm{g} / \mathrm{ml}$, a control biotinylated mouse myeloma IgG at $1 \mu \mathrm{g} / \mathrm{ml}$ (Sigma), or biotinylated lectin BS1 (L-5391; Sigma) at $1 \mu \mathrm{g} / \mathrm{ml}$ in the blocking solution overnight at $4^{\circ} \mathrm{C}$. The antigen was detected by secondary antibody where needed and $\mathrm{ABC}-\mathrm{DAB}$ method, as reported previously (Yan et al., 1997). Sections were dehydrated and coverslipped with mounting medium.

Morphological data analysis. Stained sections were examined under a light microscope. Digital images were obtained and analyzed with MetaMorph software (Universal Imaging, West Chester, PA). Sections from each animal containing cingulate cortex (between bregma $1.1 \mathrm{~mm}$ and $-0.1 \mathrm{~mm}$ ) (Franklin and Paxinos, 1996) were used for the analysis. The area of interest was manually outlined under $4 \times$ magnification. The software was programmed to measure the numbers of plaques, the average size of plaques, and the integrated plaque-staining gray scale. The percentage of area covered by plaques (plaque burden) was calculated by multiplying the number of plaques with the average size of plaques divided by the area of interest. For the analysis of microglia activation, the digital images of CD45 stained rostral hippocampus and CD11b stained frontal cortex were obtained under $10 \times$ magnification and analyzed with MetaMorph software. Two sections per animal were used for this analysis. Because the individual microglial cells were difficult to identify with the current immunostaining protocol, the $\mathrm{CD} 45$ or $\mathrm{CD} 11 \mathrm{~b}$ positive stained profiles registered by MetaMorph software were likely containing a cluster of intermingled microglial cells. All of the quantitative morphological data were analyzed by one-way ANOVA followed by Dunnett's $t$ test.

Brain preparation for $A \beta$ ELISA. Half of the brain was homogenized in $1 \mathrm{ml}$ of PBS with $3 \times$ protease inhibitor mixture (Boehringer Mannheim, Mannheim, Germany). For detection of total $\mathrm{A} \beta$ (soluble and insoluble), $200 \mu \mathrm{l}$ of the above homogenates was mixed with $800 \mu \mathrm{l}$ of $88 \%$ formic acid. Homogenates were stirred constantly overnight at room temperature to solubilize plaques. The homogenates were centrifuged at $100,000 \times g$ at room temperature in an ultracentrifuge. The supernatants were collected and neutralized with $20 \mathrm{vol}$ of $1 \mathrm{~m}$ Tris, $\mathrm{pH} 11$, and $10 \mathrm{vol}$ of SuperBlock-Tris-buffered saline (SB/TBS) containing $3 \times$ protease inhibitor mixture (Boehringer Mannheim) for ELISA. For the detection of SDS-extractable $\mathrm{A} \beta$ (nonformic acid extraction) in the brain, $200 \mu \mathrm{l}$ of the initial brain homogenate in PBS was mixed with $200 \mu$ l of $50 \mathrm{~mm}$ Tris, $150 \mathrm{~mm} \mathrm{NaCl}, 5 \mathrm{~mm}$ EDTA, 2\% SDS, 0.05\% sodium azide, $\mathrm{pH}$ 7.5, and $1 \times$ protease inhibitor mixture (Boehringer Mannheim). Homogenates were centrifuged at $16,000 \times g$ for $10 \mathrm{~min}$ at room temperature, and the supernatants were diluted 1:10 with SB-TBS. The assay was standardized by addition of $\mathrm{Ab}_{42}$ and $\mathrm{A} \beta_{40}$ peptides to a nontransgenic mouse brain homogenate processed in the same manner as the experimental samples. Sandwich ELISA assays for $\mathrm{A} \beta_{42}$ and $\mathrm{A} \beta_{40}$ were performed as described previously (Vassar et al., 1999). The data were analyzed by one-way ANOVA and then Dunnett's $t$ test.

In vitro APP processing assay. Human embryonic kidney (HEK) 293 cells stably expressing full-length human APP695 were maintained in DMEM and 10\% FBS. The cells were plated $24 \mathrm{hr}$ before treatment at 60,000 cells per well in 96-well plates. Ibuprofen and pioglitazone stock solutions were prepared in DMSO and diluted in DMEM just before treatment. Cells were treated for $18-24 \mathrm{hr}$ and the medium was collected. $\mathrm{A} \beta_{42}, \mathrm{~A} \beta_{40}$, and $\alpha \mathrm{APPs}$ levels were quantitated by standard sandwich ELISA as described previously (Vassar et al., 1999). All measurements were done in duplicate. 

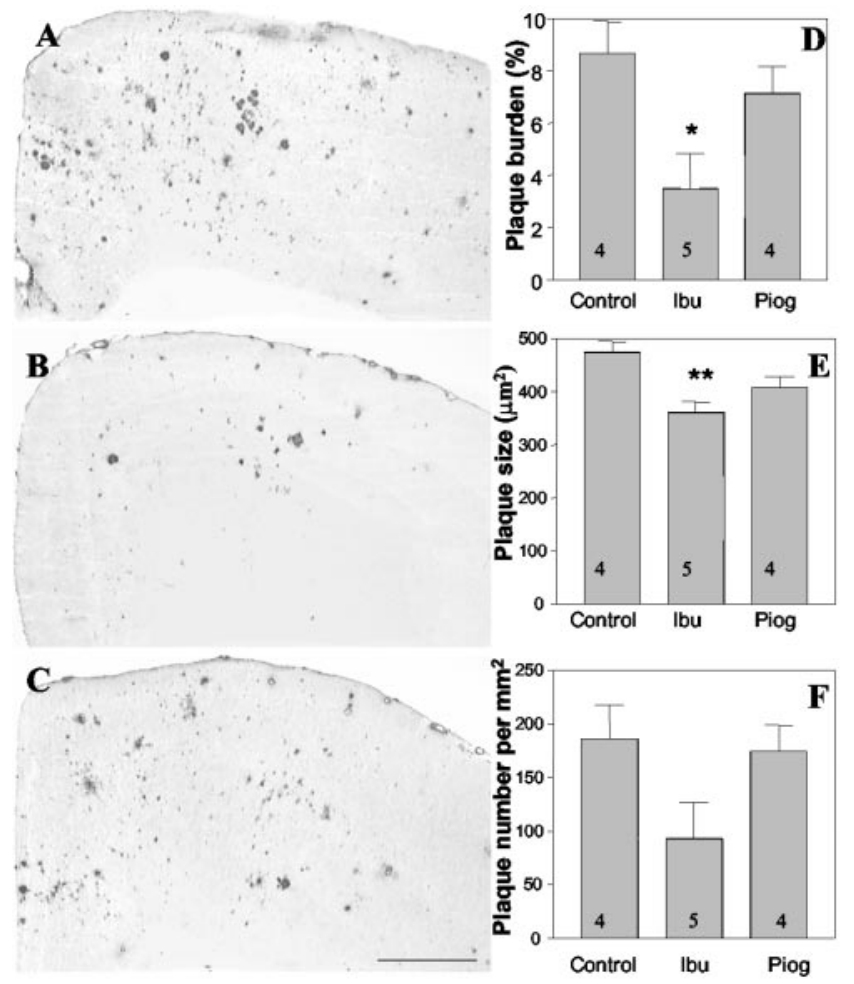

Figure 1. Ibuprofen reduces $A \beta$ plaque pathology in the $\operatorname{Tg} 2576$ mice. The $\operatorname{Tg} 2576$ mice treated with ibuprofen or pioglitazone were killed after 4 months of treatment. Coronal sections from control $(A)$, ibuprofen-treated $(B)$, and pioglitazone-treated $(C)$ mice were immunohistochemically stained for $A \beta$ using the biotinylated mouse anti-human $A \beta$ monoclonal antibody 4G8. Digital images from cingulate cortex were obtained and analyzed with MetaMorph software. $D$, The percentage of area covered by plaques (plaque burden) was calculated by multiplying the number of plaques with the average size of plaques divided by the area of interest. Ibuprofen reduced the plaque area by $60 \%\left({ }^{*} p<0.05\right)$. E, The average plaque size was computed and expressed as area per square micrometer. Ibuprofen reduced plaque size by $24 \%$ $\left.{ }^{* *} p<0.01\right)$. $F$, The average number of plaques per square micrometer in cingulate cortex was reduced in ibuprofen-treated animals by $50 \%$ but did not reach statistical significance. The number of animals used is indicated in each column. Ibu, Ibuprofen; Piog, pioglitazone.

\section{Results}

The observation that chronic NSAID treatment could diminish $\mathrm{AD}$ risk (Stewart et al., 1997; in t' Veld et al., 2001) and alter A $\beta$ plaque pathology in transgenic mice (Lim et al., 2000) led us to examine in greater detail the regulation of $\mathrm{A} \beta$ metabolism and deposition by this class of drugs. Moreover, we also wished to test whether drugs that target the nuclear receptor PPAR $\gamma$ could elicit similar effects. Examination of amyloid plaque deposition in the cingulate cortex of $\operatorname{Tg} 2576$ mice revealed that treatment with ibuprofen reduced $\mathrm{A} \beta$ deposition and plaque burden (Fig. 1). Quantitation of amyloid deposition demonstrated that ibuprofen treatment resulted in a $60 \%(p<0.05)$ decrease in the area occupied by plaques compared with control animals (Fig. 1D). This effect was primarily a consequence of a reduction in the number of plaques, which was diminished by $50 \%$ (Fig. $1 F$ ). We observed an overall reduction in the size of the individual plaques by $24 \%(p<0.01)$ (Fig. $1 E)$ in the ibuprofen-treated animals. Pioglitazone-treated animals exhibited no significant changes in any of these parameters.

We investigated whether the drug-mediated amelioration of plaque pathology was linked to changes in APP processing and $\mathrm{A} \beta$ levels in the brain. Analysis of Tg2576 mice that were treated for 4 months with either ibuprofen or the PPAR $\gamma$ agonist piogli-
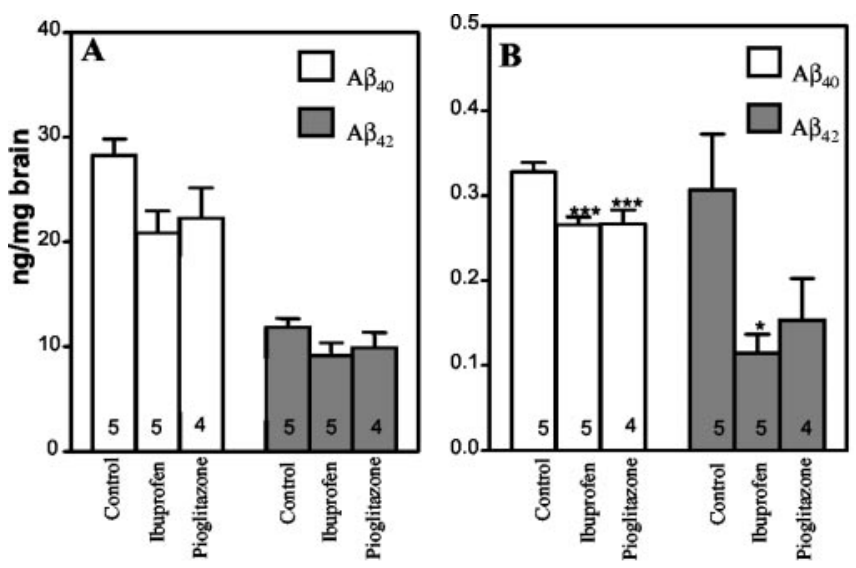

Figure 2. Ibuprofen and pioglitazone alter $A \beta$ peptide levels in the $\operatorname{Tg} 2576$ mice. $\operatorname{Tg} 2576$ mice were administered ibuprofen and pioglitazone or unsupplemented chow for 4 months. Total and SDS-soluble $A \beta_{40}$ and $A \beta_{42}$ levels were measured by sandwich ELISA from cerebral hemispheres. $A$, Formic acid-solubilized $A \beta_{40}$ and $A \beta_{42}$ levels. Drug treatment did not significantly affect either $A \beta_{40}$ or $A \beta_{42}$. B, SDS-soluble $A \beta_{40}$ and $A \beta_{42}$ levels. $A \beta_{40}$ levels were decreased in the brains of pioglitazone-treated $\left({ }^{* *} p<0.001\right)$ and ibuprofen-treated $\left({ }^{* *} p<\right.$ 0.001 ) animals. $A \beta_{42}$ levels were reduced by ibuprofen treatment $\left({ }^{*} p<0.05\right)$. The number of animals used is indicated in each column.

tazone revealed that the total amount of formic acid-solubilized $\mathrm{A} \beta_{40}$ or $\mathrm{A} \beta_{42}$ was modestly reduced. The ibuprofen-treated animals exhibited a $26 \%$ reduction in $\mathrm{A} \beta_{40}$, whereas pioglitazone treatment resulted in a $21 \%$ reduction in $\mathrm{A} \beta_{40}$; however, neither reached statistical significance (Fig. $2 A$ ). However, quantitation of SDS-soluble $A \beta$ levels in the brains of these mice demonstrated that both ibuprofen and pioglitazone reduced $\mathrm{A} \beta_{40}$ levels by $19 \%$, a difference that was statistically significant compared with control animals $(p<0.05)$ (Fig. $2 B)$. Importantly, there was a striking reduction in the levels of SDS-soluble $A \beta_{42}$ after drug treatment. Ibuprofen treatment reduced SDS-soluble A $\beta_{42}$ levels by $63 \%(p<0.05)$. Pioglitazone-treated animals exhibited an overall reduction of SDS-soluble $\mathrm{A} \beta_{42}$ levels of $50 \%$, but this effect did not reach statistical significance. These data demonstrate that anti-inflammatory drug therapy alters the levels of amyloidogenic $\mathrm{A} \beta$ peptides in the brain.

It has been argued that the principal cellular target of NSAIDs are microglia that are phenotypically activated as a consequence of amyloid deposition. We evaluated microglia activation and abundance by staining for cell surface markers, which are elevated after activation of these cells. Ibuprofen treatment significantly reduced the number of CD45-positive microglia in hippocampus (39\% reduction; $p<0.05$ ) (Fig. $3 A, B)$. CD45 is a tyrosine phosphatase that plays critical roles in immune receptor signaling. CD45 expression levels are elevated in reactive microglia in the AD brain (Masliah et al., 1991) and in murine models of the disease (Wilcock et al., 2001). We also found that there was an ibuprofen-mediated $49 \%$ reduction $(p<0.05)$ in the expression of the complement receptor 3 subunit CD11b (Fig. 4). $\mathrm{CD} 11 \mathrm{~b}$ (also known as the $\alpha_{\mathrm{m}} \beta_{2}$ integrin and Mac1) is a sensitive marker of microglial activation in the AD brain (Mackenzie and Munoz, 1998) and in murine models of the disease (SturchlerPierrat et al., 1997). Pioglitazone treatment did not result in a significant change in the microglial expression of either CD45 or CD11b. We were unable to observe a significant change in microglial phosphotyrosine levels in response to ibuprofen, as reported previously by Lim and colleagues (2001) (data not shown). Activated microglia are found associated with amyloid plaques, thus 


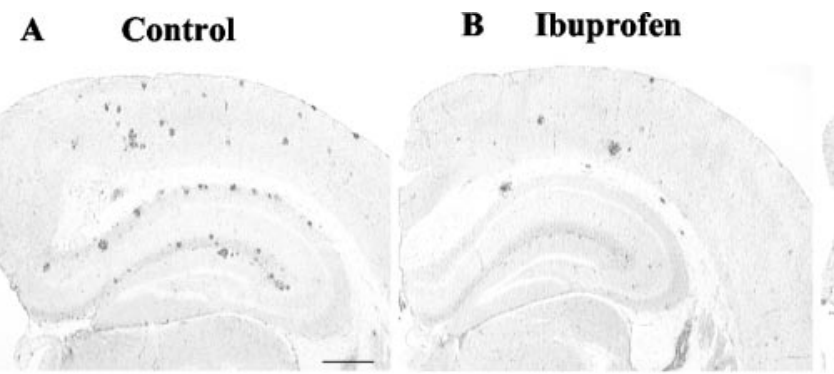

\section{Pioglitazone}

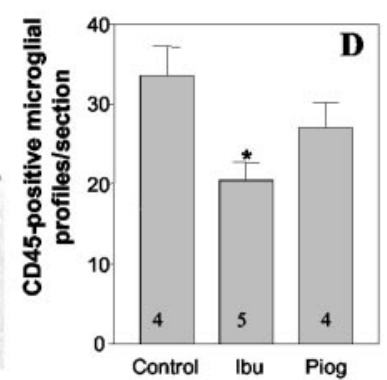

Figure 3. Ibuprofen reduces the number of $C D 45$-positive microglia. The brains of control $\operatorname{Tg} 2576$ mice $(A)$ and those treated for 4 months with ibuprofen $(B)$ or pioglitazone $(C)$ were stained for CD45. There was a $39 \%$ reduction in the number of CD45-positive microglial cells in the hippocampus of ibuprofen-treated mice $\left({ }^{*} p<0.05\right)$. The number of animals used is indicated in each column (D). Ibu, Ibuprofen; Piog, pioglitazone.

\section{A Control}

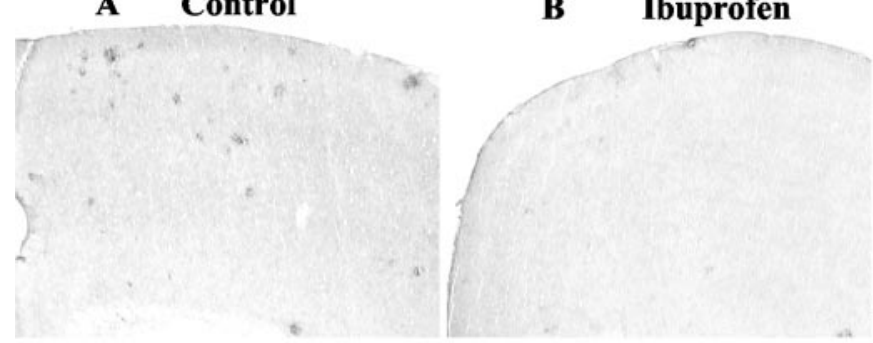

\section{Pioglitazone}

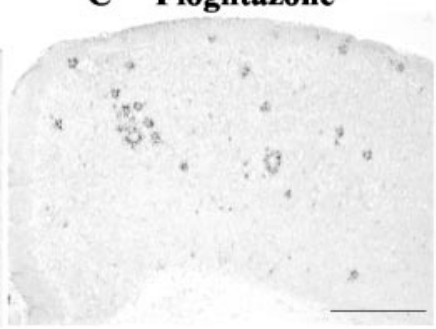

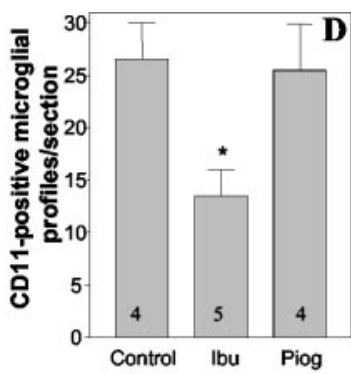

Figure 4. Ibuprofen reduces the number of $C D 11 b$-positive microglia. The brains of control $\mathrm{Tg} 2576$ mice $(A)$ and those treated for 4 months with ibuprofen $(B)$ or pioglitazone $(C)$ were stained for CD11b. There was a $49 \%$ reduction ( ${ }^{*} p<0.05$ ) in the number of CD11b-positive microglial cells in the frontal cortex of ibuprofen-treated mice. The number of animals used is indicated in each column (D).

the decrease in the number of reactive cells is correlated with reduced plaque burden.

A number of NSAIDs, including ibuprofen, have recently been reported to selectively regulate the processing of APP, and it has been argued that this effect may underlie their beneficial effects in AD (Weggen et al., 2001). NSAID treatment of APPoverexpressing cells was reported to result in a preferential reduction in the production of $\mathrm{A} \beta_{42}$ and a parallel increase in $\mathrm{A} \beta_{38}$, although it had no effect on $\mathrm{A} \beta_{40}$ (Weggen et al., 2001). We tested whether ibuprofen and pioglitazone altered $\mathrm{A} \beta$ production in HEK293 cells overexpressing human APP. Ibuprofen treatment resulted in a dramatic reduction in the levels of $\mathrm{A} \beta_{42}$ secreted into the medium, although it had no effect on $\mathrm{A} \beta_{40}$ levels (Fig. 5A). Ibuprofen had no effect on the $\alpha$-secretase cleavage of APP, which was used as an indirect measure of drug effects on cellular viability and metabolism. Pioglitazone had no significant effect on $\mathrm{A} \beta$ production (Fig. $5 B$ ).

\section{Discussion}

The mechanisms by which anti-inflammatory agents affect $\mathrm{AD}$ risk in humans and amyloid pathology in animal models of the disease are likely to be complex and diverse. We report that treatment of Tg2576 mice with ibuprofen during the period in which $\mathrm{A} \beta$ is deposited in the brain resulted in significant alterations in amyloid plaque pathology, $\mathrm{A} \beta$ production, and microglial activation. These data provide strong evidence that ibuprofen, and likely other NSAIDs, have multiple cellular and molecular targets.

The widely accepted target of the action of NSAIDs are the cyclooxygenases, and much of the discussion on both of the mechanisms underlying the effects of these drugs and the design of clinical trials has focused on these enzymes and their products (Yermakova and O'Banion, 2000; Pasinetti, 2001; Aisen, 2002).
Despite considerable investigative activity, there are few compelling data to indicate that these enzymes play critical roles in eliciting neuronal death or otherwise exacerbate the pathophysiology of AD. The recent report of the failure of clinical trials using COX-2-specific inhibitors in AD patients has served to further diminish confidence that cyclooxygenases are the biologically relevant target of NSAID action in AD (Sainati et al., 2000). It has been demonstrated conclusively that these enzymes are not involved with the selective reduction in $\mathrm{A} \beta_{42}$ levels (Weggen et al., 2001). Moreover, it is unlikely that the broad range of antiinflammatory actions of NSAIDs could arise simply from COX inhibition. Alternate mechanisms of NSAID actions have been reported. Ibuprofen and other NSAIDs have been found to inhibit several distinct signal transduction cascades (Tegeder et al., 2001; Baek et al., 2002). These effects have not been examined extensively, and no consistent conclusions can be drawn from the existing data. A more detailed examination of these mechanisms is clearly required.

The principal effect of ibuprofen treatment in Tg2576 mice was a very significant reduction in plaque burden after 4 months of treatment. The magnitude of the decrease in the number of plaques that we observed was similar to those reported by Lim et al. (2000) (52.6 vs 51\%), as was the reduction in area occupied by amyloid plaques ( $55.9 \mathrm{vs} 60 \%$ ). The reduction in amyloid burden observed here is also consistent with that reported recently by Jantzen et al. (2002) in mice treated with ibuprofen or a flurbiprofen derivative.

We found that ibuprofen treatment resulted in only a modest and statistically insignificant decrease in total insoluble $A \beta$ in the brains of $\mathrm{Tg} 2576$ mice. This finding is quantitatively different from that reported by Lim et al. (2000). These authors reported a $40 \%$ decrease in total $2 \%$ SDS-insoluble $A \beta$ in "residual" regions 

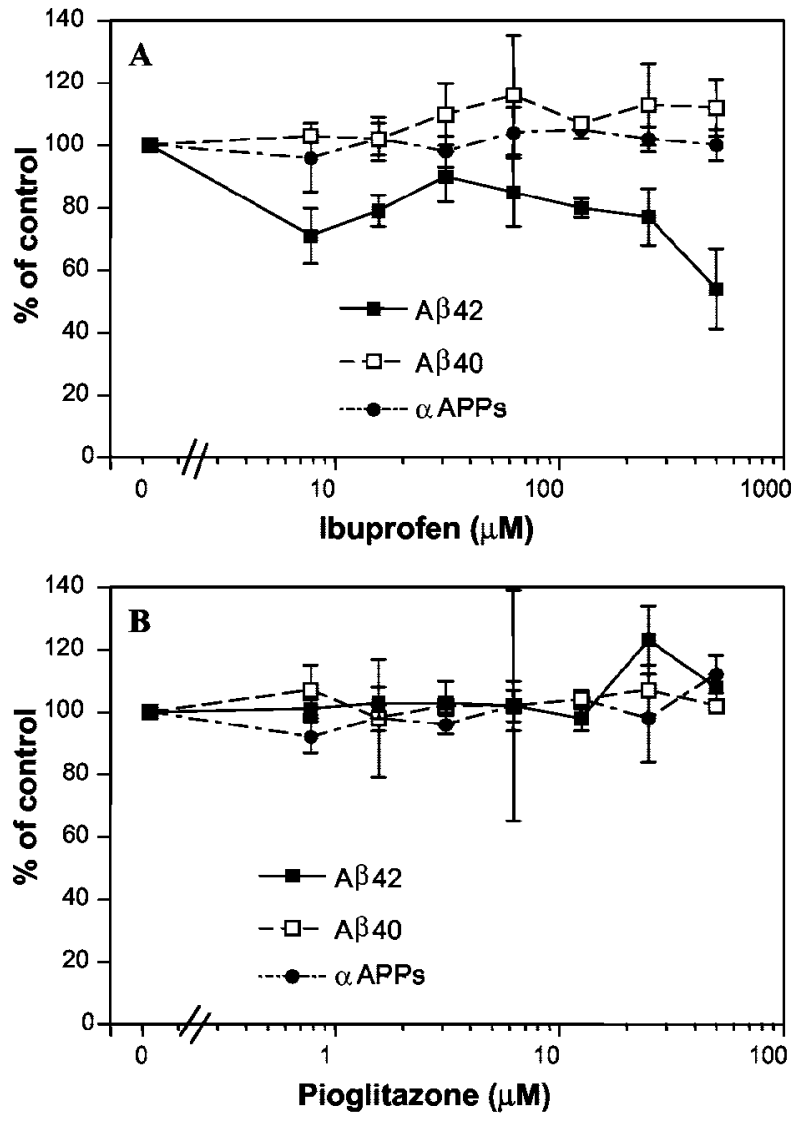

Figure 5. Effect of anti-inflammatory drugs on $A \beta_{40}$ and $A \beta_{42}$ generation in APPoverexpressing cells. Human embryonic kidney 293 cells stably expressing full-length human APP695 were treated for $18-24 \mathrm{hr}$ with the indicated concentration of ibuprofen or pioglitazone, and the medium was collected. $A \beta_{42}, A \beta_{40}$, and $\alpha$ APPs levels were quantitated by standard sandwich ELISA. A, Ibuprofen, $A \beta_{40}(\square), A \beta_{42}(\square)$, and $\alpha$ APPs $(\mathbf{O})$, levels are shown \pm SD. B, Pioglitazone, $A \beta_{40}(\square), A \beta_{42}(\square)$, and $\alpha A P P s(-)$ levels are shown \pm SD.

of the cortex with smaller reductions ranging from 20 to $35 \%$ in hippocampus, entorhinal cortex, and piriform cortex. Notably, they reported a $34 \%$ decrease in soluble $\mathrm{A} \beta$ in these animals; however, these changes did not reach statistical significance. These authors have subsequently reported that a 3 month treatment of Tg2576 mice with ibuprofen resulted in an $\sim 50 \%$ reduction in total soluble $\mathrm{A} \beta$, total insoluble $\mathrm{A} \beta$, and $\mathrm{A} \beta_{42}$; however, this change was restricted to the entorhinal cortex. $A \beta$ levels in other brain regions were not significantly different (Lim et al., 2001). Thus, whereas our data on plaque pathology are similar to those reported previously, we obtained a quite different outcome with respect to alterations in the levels of the individual $\mathrm{A} \beta$ species that contribute to the plaque. Although our measurements were performed using the entire cerebral hemisphere rather than subregions of the brain, it seems unlikely that this can account for the different outcomes of the experiments. We found that although we observed a $60 \%$ reduction in plaque burden by ibuprofen, there was only a $26 \%$ decrease in total $\mathrm{A} \beta$ levels. This finding suggests that not all $\mathrm{A} \beta$ is plaque-associated in these animals. A similar disparity between amyloid burden and total $\mathrm{A} \beta$ peptide levels has also been observed by Janus and colleagues (2000) after $A \beta$ immunization. The basis of this effect is not clear but may represent the redistribution of $\mathrm{A} \beta$ from plaques into a soluble pool.

The primary source of $\mathrm{A} \beta$ in the brain are neurons, and the present data demonstrate that ibuprofen treatment dramatically affects the buildup of the highly amyloidogenic $\mathrm{A} \beta_{42}$ species produced by these cells. Importantly, there was no significant change in SDSsoluble $\mathrm{A} \beta_{40}$ levels. Our observation of a selective decrease in $\mathrm{A} \beta_{42}$ levels after ibuprofen treatment of transgenic mice is consistent with data recently reported by Weggen et al. (2001). These authors found that a $3 \mathrm{~d}$ treatment of Tg2576 mice with ibuprofen resulted in an $\sim 40 \%$ decrease in soluble $\mathrm{A} \beta_{42}$ levels in the brains of these mice without a significant change in $\mathrm{A} \beta_{40}$ levels. We also demonstrate, using in vitro assays in cells overexpressing APP, that ibuprofen affects APP processing, resulting in a dramatic and selective reduction in the levels of $A \beta_{42}$ released by the cells but having no effect on $\mathrm{A} \beta_{40}$ production. These latter observations serve to verify the findings reported by Weggen et al. (2001) using a similar assay system. This selective reduction in $\mathrm{A} \beta_{42}$ levels and a concomitant increase in $\mathrm{A} \beta_{38}$ has been postulated to arise from a drug-mediated alteration in $\gamma$-secretase specificity, although the precise mechanisms subserving this effect are presently unclear.

Microglial activation has been argued to contribute to the progressive course of $\mathrm{AD}$ because of elaboration of a large array of proinflammatory molecules that mediate, in part, the neuronal loss observed in the disease (Kalaria, 1999; Akiyama et al., 2000). We found that ibuprofen treatment of Tg2576 mice resulted in a $40 \%$ reduction in CD 45 -positive microglia and a $49 \%$ decrease in CD11b expression. The induction of CD45 and CD11b expression accompanies the phenotypic activation of these cells in the AD brain (Masliah et al., 1991, Mackenzie et al., 1998). These data are consistent with the findings of Lim et al. (2000), who reported an ibuprofen-mediated decrease in microglial activation, as reflected by phosphotyrosine staining, another marker of microglial activation. We were unable to observe analogous effects with this marker. The ibuprofen-mediated suppression of microglial activation observed here and by Lim et al. (2000) is in contrast to data reported by Jantzen et al. (2002), who reported that mice doubly transgenic for APP and PS1 exhibited a small but not significant increase in major histocompatibility complex IIpositive profiles when treated with ibuprofen for 5 months. These data were interpreted as reflective of microglia activation by the ibuprofen treatment.

It is not obvious how ibuprofen elicits effects on the microglia. We argued that ibuprofen may suppress microglial activation through its ability to activate the nuclear receptor PPAR $\gamma$ (Landreth and Heneka, 2001). This study evaluated the effects of the highly specific and potent PPAR $\gamma$ agonist pioglitazone on the basis of our previous observations that PPAR $\gamma$ activation robustly antagonized the $\mathrm{A} \beta$-mediated activation of microglia and the production of a number of proinflammatory and neurotoxic molecules (Combs et al., 2000). Pioglitazone treatment effected a change in A $\beta$ peptide levels; however, the magnitude of this change was too small to translate to a significant effect on plaque pathology. Specifically, we observed that pioglitazone had only a modest effect on total $\mathrm{A} \beta$ levels and had no detectable effect on microglial activation in the Tg2576 mice. Pioglitazone has been reported to pass the blood-brain barrier (Kiyota et al., 1997); however, it seems likely that the dose used in this study was insufficient to result in levels of the drug in the brain required to elicit the robust activation of this nuclear receptor $(\mathrm{G}$. Landreth, unpublished observations). In the cell-based assay, which circumvents problems of in vivo pharmacokinetics and blood-brain barrier penetration, pioglitazone did not show the specific $\mathrm{A} \beta_{42^{-}}$ lowering effect observed by Weggen et al. (2001) for NSAIDs. At high pioglitazone concentrations, a reduction in all secreted APP metabolites, which we interpret as nonspecific toxicity was observed (data not shown). Therefore, if the amyloid burden reduction in ibuprofen-treated mice is indeed the result of a reduction in $\mathrm{A} \beta 42$ production, this is unlikely mediated through the PPAR $\gamma$ pathway. 
In summary, these data support the use of anti-inflammatory drug treatment in $\mathrm{AD}$, at least for those agents that effect a reduction in the levels of amyloidogenic peptides and the proinflammatory response of microglial cells. The additional mechanisms of the action of ibuprofen remain unclear, and it remains a formal possibility that ibuprofen affects the clearance of $A \beta$ from the brain or intervenes in processes mediating the fibrilization and deposition of it. However, the selective ibuprofen effect on the $\mathrm{A} \beta_{42}$ isoform, both in tissue culture and in our chronic in vivo treatment, is explained most parsimoniously by a modulation of $\gamma$-secretase activity, which leads to reduction in $\mathrm{A} \beta_{42}$ production.

\section{References}

Aisen PS (2002) Anti-inflammatory agents in Alzheimer's disease. Curr Neurol Neurosci Rep 2:405-409.

Akiyama H, Barger S, Barnum S, Bradt B, Bauer J, Cole GM, Cooper NR, Eikelenboom P, Emmerling M, Fiebich BL, Finch CE, Frautschy S, Griffin WS, Hampel H, Hull M, Landreth G, Lue L, Mrak R, Mackenzie IR, McGeer PL, et al. (2000) Inflammation and Alzheimer's disease. Neurobiol Aging 21:383-421.

Baek SH, Ohgi KA, Rose DW, Koo EH, Glass CK, Rosenfeld MG (2002) Exchange of N-CoR corepressor and Tip60 coactivator complexes links gene expression by NF-kappaB and beta-amyloid precursor protein. Cell 110:55-67.

Benzing WC, Wujek JR, Ward EK, Shaffer D, Ashe KH, Younkin SG, Brunden KR (1999) Evidence for glial-mediated inflammation in aged APP(SW) transgenic mice. Neurobiol Aging 20:581-589.

Berger J, Moller DE (2002) The mechanisms of action of PPARs. Annu Rev Med 53:409-435.

Bornemann KD, Wiederhold KH, Pauli C, Ermini F, Stalder M, Schnell L, Sommer B, Jucker M, Staufenbiel M (2001) Abeta-induced inflammatory processes in microglia cells of APP23 transgenic mice. Am J Pathol 158:63-73.

Citron M (2002) Alzheimer's disease: treatments in discovery and development. Nat Neurosci [Suppl] 5:1055-1057.

Combs CK, Johnson DE, Karlo JC, Cannady SB, Landreth GE (2000) Inflammatory mechanisms in Alzheimer's disease: inhibition of $\beta$-amyloidstimulated proinflammatory responses and neurotoxicity by PPAR $\gamma$ agonists. J Neurosci 20:558-567.

Delerive P, Fruchart JC, Staels B (2001) Peroxisome proliferator-activated receptors in inflammation control. J Endocrinol 169:453-459.

Franklin KBJ and Paxinos G (1996) Mouse brain in stereotaxic coordinates. New York: Morgan Kaufmann.

Frautschy SA, Yang F, Irrizarry M, Hyman B, Saido TC, Hsiao K, Cole GM (1998) Microglial response to amyloid plaques in APPsw transgenic mice. Am J Pathol 152:307-317.

Heneka MT, Klockgether T, Feinstein DL (2000) Peroxisome proliferatoractivated receptor- $\gamma$ ligands reduce neuronal inducible nitric oxide synthase expression and cell death in vivo. J Neurosci 20:6862-6867.

in t' Veld BA, Ruitenberg A, Hofman A, Launer LJ, van Duijn CM, Stijnen T, Breteler MM, Stricker BH (2001) Nonsteroidal anti-inflammatory drugs and the risk of Alzheimer's disease. N Engl J Med 345:1515-1521.

Jantzen PT, Connor KE, DiCarlo G, Wenk GL, Wallace JL, Rojiani AM, Coppola D, Morgan D, Gordon MN (2002) Microglial activation and $\beta$-amyloid deposit reduction caused by a nitric oxide-releasing nonsteroidal anti-inflammatory drug in amyloid precursor protein plus presenilin-transgenic mice. J Neurosci 22:2246-2254.

Janus C, Pearson J, McLaurin J, Mathews PM, Jiang Y, Schmidt SD, Chishti MA, Horne P, Heslin D, French J, Mount HT, Nixon RA, Mercken M, Bergeron C, Fraser PE, St George-Hyslop P, Westaway D (2000) A beta peptide immunization reduces behavioural impairment and plaques in a model of Alzheimer's disease. Nature 408:979-982.

Kalaria RN (1999) Microglia and Alzheimer's disease. Curr Opin Hematol 6:15-24.

Kiyota Y, Kondo T, Maeshiba Y, Hashimoto A, Yamashita K, Yoshimura Y, Motohashi M, TanayamaS (1997) Studies on the metabolism of the new antidiabetic agent pioglitazone. Identification of metabolites in rats and dogs. Arzneimittelforschung 47:22-28.

Landreth GE, Heneka MT (2001) Anti-inflammatory actions of peroxisome proliferator-activated receptor gamma agonists in Alzheimer's disease. Neurobiol Aging 22:937-944.

Lehmann JM, Lenhard JM, Oliver BB, Ringold GM, Kliewer SA (1997) Peroxisome proliferator-activated receptors alpha and gamma are activated by indomethacin and other non-steroidal anti-inflammatory drugs. J Biol Chem 272:3406-3410.

Lim GP, Yang F, Chu T, Chen P, Beech W, Teter B, Tran T, Ubeda O, Ashe KH, Frautschy SA, Cole GM (2000) Ibuprofen suppresses plaque pathology and inflammation in a mouse model for Alzheimer's disease. J Neurosci 20:5709-5714.

Lim GP, Yang F, Chu T, Gahtan E, Ubeda O, Beech W, Overmier JB, HsiaoAshec K, Frautschy SA, Cole GM (2001) Ibuprofen effects on Alzheimer pathology and open field activity in APPsw transgenic mice. Neurobiol Aging 22:983-991.

Mackenzie IR, Munoz DG (1998) Nonsteroidal anti-inflammatory drug use and Alzheimer-type pathology in aging. Neurology 50:986-990.

Masliah E, Mallory M, Hansen L, Alford M, Albright T, Terry R, Shapiro P, Sundsmo M, Saitoh T (1991) Immunoreactivity of CD45, a protein phosphotyrosine phosphatase, in Alzheimer's disease. Acta Neuropathol (Berl) 83:12-20.

McGeer PL, Schulzer M, McGeer EG (1996) Arthritis and anti-inflammatory agents as possible protective factors for Alzheimer's disease: a review of 17 epidemiologic studies. Neurology 47:425-432.

Mehlhorn G, Hollborn M, Schliebs R (2000) Induction of cytokines in glial cells surrounding cortical beta-amyloid plaques in transgenic Tg2576 mice with Alzheimer pathology. Int J Dev Neurosci 18:423-431.

Pasinetti GM (2001) Cyclooxygenase and Alzheimer's disease: implications for preventive initiatives to slow the progression of clinical dementia. Arch Gerontol Geriatr 33:13-28.

Rich JB, Rasmusson DX, Folstein MF, Carson KA, Kawas C, Brandt J (1995) Nonsteroidal anti-inflammatory drugs in Alzheimer's disease. Neurology 45:51-55.

Sainati S, Ingram D, Talwalker G, Geis G (2000) Results of a double-blind, randomized, placebo-controlled study of celecoxib in the treatment of Alzheimer's disease. Sixth International Stockholm/Springfield Symposium on Advances in Alzheimer Therapy, Stockholm, April.

Stalder M, Phinney A, Probst A, Sommer B, Staufenbiel M, Jucker M (1999) Association of microglia with amyloid plaques in brains of APP23 transgenic mice. Am J Pathol 154:1673-1684.

Stalder M, Deller T, Staufenbiel M, Jucker M (2001) 3D-reconstruction of microglia and amyloid in APP23 transgenic mice: no evidence of intracellular amyloid. Neurobiol Aging 22:427-434.

Stewart WF, Kawas C, Corrada M, Metter EJ (1997) Risk of Alzheimer's disease and duration of NSAID use. Neurology 48:626-632.

Sturchler-Pierrat C, Abramowski D, Duke M, Wiederhold KH, Mistl C, Rothacher S, Ledermann B, Burki K, Frey P, Paganetti PA, Waridel C, Calhoun ME, Jucker M, Probst A, Staufenbiel M, Sommer B (1997) Two amyloid precursor protein transgenic mouse models with Alzheimer disease-like pathology. Proc Natl Acad Sci USA 94:13287-13292.

Tegeder I, Pfeilschifter P, Geisslinger G (2001) Cyclooxygenase-independent actions of cyclooxygenase inhibitors. FASEB J 15:2057-2072.

Vassar R, Bennett BD, Babu-Khan S, Kahn S, Mendiaz EA, Denis P, Teplow DB, Ross S, Amarante P, Loeloff R, Luo Y, Fisher S, Fuller J, Edenson S Lile J, Jarosinski MA, Biere AL, Curran E, Burgess T, Louis JC, et al. (1999) Beta-secretase cleavage of Alzheimer's amyloid precursor protein by the transmembrane aspartic protease BACE. Science 286:735-741.

Weggen S, Eriksen JL, Das P, Sagi SA, Wang R, Pietrzik CU, Findlay KA, Smith TE, Murphy MP, Bulter T, Kang DE, Marquez-Sterling N, Golde TE, Koo EH (2001) A subset of NSAIDs lower amyloidogenic Abeta42 independently of cyclooxygenase activity. Nature 414:212-216.

Wilcock DM, Gordon MN, Ugen KE, Gottschall PE, DiCarlo G, Dickey C, Boyett KW, Jantzen PT, Connor KE, Melachrino J, Hardy J, Morgan D (2001) Number of Abeta inoculations in APP + PS1 transgenic mice influences antibody titers, microglial activation, and congophilic plaque levels. DNA Cell Biol 20:731-736.

Yan Q, Radeke MJ, Matheson CR, Talvenheimo J, Welcher AA, Feinstein SC (1997) Immunocytochemical localization of TrkB in the central nervous system of the adult rat. J Comp Neurol 378:135-157.

Yermakova A, O'Banion MK (2000) Cyclooxygenases in the central nervous system: implications for treatment of neurological disorders. Curr Pharmacol Res 6:1755-1776. 